\title{
SEASONAL VARIATION OF STRATOSPHERIC AEROSOLS AS OBSERVED BY LIDAR AT TOYOKAWA
}

\author{
M. Takagi and A. Iwata \\ Research Institute of Atmospherics, Nagoya University, \\ Toyokawa 442, Japan
}

\begin{abstract}
Lidar observations at Toyokawa during 4 years (1983-1986) in the decay phase of El Chichon cloud were examined. Annual variation of stratospheric aerosol content deduced as the deviation from a properly assumed decay curve has maximum in winter and minimum in summer. The amplitude of seasonal deviation is of almost same rate every year irrespective of the progress of decaying. The variation of content is marked in the main aerosol layer of vertical width 3.5 to $4 \mathrm{~km}$. The center altitude of the layer is 17 to $19 \mathrm{~km}$, and about $1 \mathrm{~km}$ higher in summer than in winter.
\end{abstract}

1. Introduction

Seasonal variation of stratospheric aerosols during volcanically quiescent period was first analyzed by Hofmann et al. $(1975,1976)$ based on their number of balloon-borne dust sonde measurements in 1971-1974. They confirmed that the stratospheric aerosol burden showed the winter maximum and summer minimum in both hemispheres and had a reversed relation to the height of tropopause. Bigg (1976) also reported from the results of balloon soundings in Australia in 1969-1974 that, especially in the lowermost stratosphere near the tropopause, the winter maximum appeared for small size range aerosols less than $0.2 \mu \mathrm{m}$ diameter, which was followed by the spring maximum in larger size range.

In October 1974, Mt. Fuego erupted and the aftereffect was recognized for about 3 years (e.g. Hofmann and Rosen, 1987). Superposed on the decaying volcanic aftereffect, some lidar observations found the similar seasonal variations as above though the detailed varying pattern showed difference respectively in part (Reiter, 1979; Iwasaka, 1981).

Since 1979 the stratosphere came into a heavily perturbed period due to successive volcanic activities, such as La Soufrier (April 1979), Sierra Negra (November 1979), St. Helens (May 1980), Alaid (April 1981), Pagan (May 1981), and El Chichon (April 1982). The usual seasonal pattern was obscured by these predominating volcanic loadings. After the El Chichon event which is thought to be one of the biggest aerosol supplies to the stratosphere in this century, the effect of it has lasted long time. However, it does not seem that there was such a big loading as severely modifying the steady decay of El Chichon cloud toward the background level. Our lidar system using the wavelength of $532 \mathrm{~nm}$ was constructed at Toyokawa $\left(34.8^{\circ} \mathrm{N}, 137.4^{\circ} \mathrm{E}\right)$ in 1982 and entered regular operation since December 1982. It was just the time that the monotonous decay of E1 Chichon cloud in the northern mid-latitudes had started. This paper discusses the seasonal variations superposed on the decay trend observed by the lidar system for about 4 years from March 1983 to December 1986. The lidar specifications were given in detail by Iwata et al. (1983).

2. General trend of stratospheric aerosol content in 1983-1986

Indices generally used in lidar observations to run after the time 
variation of aerosol burden are the peak value in the profile of backscattering ratio $R$ and the integrated backscattering coefficient (IBSC) of aerosols in the stratosphere. The former is basically the ratio of measured backscattered signal to theoretically calculated backscatter of neutral molecules, and therefore the quantity $\mathrm{R}-1$ corresponds to the mixing ratio of aerosols to the atmosphere at respective altitudes. The latter is columnar integral of aerosol backscattering coefficient in the stratosphere, which is determined from the value of $\mathrm{R}-1$ and the molecular density profile. It corresponds to the total aerosol content optically seen within an integrated altitude range. As far as we are concerned with a large number of aerosol vertical distributions in a long time scale, the correlation between both indices is usually high.

Figure 1 shows the integrated backscattering coefficient of aerosols in the altitude range 13.5 to $30 \mathrm{~km}$ versus time from March 1983 to December 1986. The lower limit of integration is chosen at $13.5 \mathrm{~km}$ because this level is usually of low aerosol content and roughly average altitude of tropopause. Occasional cirrus seldom appears above this level. The observations before March 1983 were excluded by the reason that a remarkable descent of main aerosol layer altitude was found in this period (Iwata and Takagi, 1984). Several volcanoes which might have possibility to give some influence to the stratosphere are also shown under the abscissa. It is really difficult to estimate how much disturbances were introduced on the general decay trend by these eruptions, but so far as we take a quick look at the time variation in Fig. 1, their effects may not be considered as the very important source of deforming a smooth decay curve representing the aftereffect of El Chichon. For example, the Ruiz eruption in November

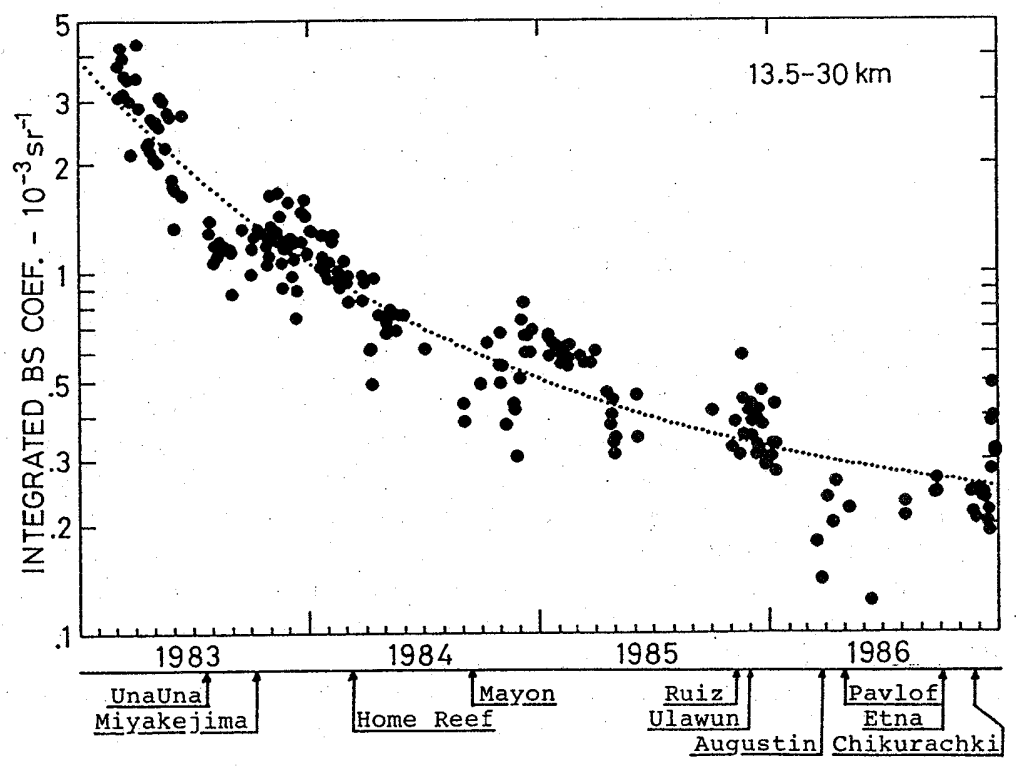

Fig. 1. Time variation of integrated aerosol backscattering coefficient in the altitude range of $13.5-30 \mathrm{~km}$. The smooth dotted curve is obtained with least squares fitting on the assumption that the logarithm of data follows an exponential decay. The main volcanic activities during the period are shown under the abscissa. 
1985, which was world-widely informed because of the heavy casualties in men and beasts, gave a peak backscattering ratio of about 2.0 at $21 \mathrm{~km}$ altitude as a relatively thin aerosol layer on several days in the beginning of January 1986 (Iwata et al., 1986). This peak value is considerably high as compared with 1.33, the mean peak value during December 1985, but the effect did not last so long and was not so big as clearly influencing the aerosol column content.

The aerosol burden during the 4 years could be said to be in a steady decay toward the background level. The initial value at the beginning of decay is as high as 20 times of the final value. It is not al ways realistic to represent the long term and wide range trend with an exponential decay of fixed time constant, because the magnitude of variance is controlled almost only by the part of high absolute values in the early stage of decay. The smooth dotted curve in Fig. 1 is obtained with the least squares fitting on the assumption that the logarithm of integrated backscattering coefficient comes down with a fixed time constant toward a certain background value, as shown in the following expression.

$$
\begin{aligned}
\log \{\operatorname{IBSC}(t)\}= & \log \{\operatorname{IBSC}(t=\infty)\} \\
& +[\log \{\operatorname{IBSC}(t=0)\}-\log \{\operatorname{IBSC}(t=\infty)\}] \exp (-t / T)
\end{aligned}
$$

The time constant $T$ and the background $\operatorname{IBSC}(t=\infty)$ are calculated to be 672 days and $1.77 \times 10^{-4} \mathrm{sr}^{-1}$, respectively. (Comparing to this, the least squares fitting on the similar expression for IBSC in place of $\log$ \{IBSC gives 193 days and $3.82 \times 10^{-4} \mathrm{sr}^{-1}$.) The assumption above means that the time constant representing instantaneous decay of IBSC becomes gradually long toward the final value of 672 days (Refer to Appendix). Calculation gives the instantaneous decay constants $207,311,417$, and 504 days, respectively, at the beginning of each year 1983-1986. The results suggest that the various processes causing decay, which involves the balance between the aerosol production and dissipation, such as occasional small scale volcanic supply, gas to particle conversion, circulation and trans-

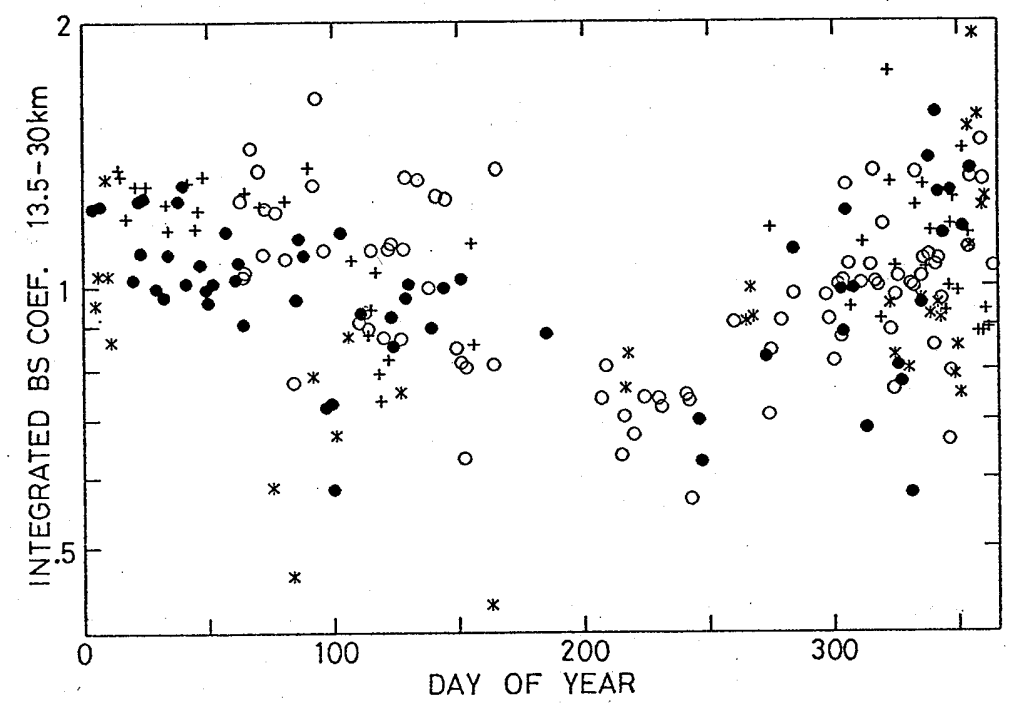

Fig. 2. Annual variation of the ratio to decay curve for the integrated aerosol backscattering coefficient in $13.5-30 \mathrm{~km}$. The different marks correspond to the respective years, $01983,-1984,+1985$, and $* 1986$. 
portation of gas and particles, exchange to the troposphere, etc., alter their respective weight according to the lapse of time.

The analyses hereafter are based on the deviation of individual data from the decay curve thus obtained.

3. Annual pattern of deviation from the decay curve

As seen in Fig. 1, the deviation from the decay curve shows, on an average, a regular yearly pattern, mainly upward in winter and downward in summer. To see more clearly this point, the ratio of individual data to the value of curve (logarithmic deviation from the curve) is shown in Fig. 2 on the time base of a year. The different marks correspond to the respective years. The annual pattern displays clearly the winter maximum and summer minimum, though accompanied by wide dispersion. It is noted that there is little year-to-year difference, notwithstanding very wide change of the absolute aerosol content in the progress of decay.

Figure 3 shows the annual patterns of some parameters by reducing to the respective 90-days running mean variations. The full curve (a) is the same parameter as Fig. 2. The maximum appears in January-February (day of year 0-60). The gradual decrease follows it until June, then the curve drops to the minimum in the end of July. From August it turns to increase toward the January maximum. The amplitude of annual variation amounts to $25 \%$.

The dotted curve (b) and the broken curve (c) in Fig. 3 are for different integration ranges respectively, tropopause-30 km and $20-30 \mathrm{~km}$. The annual variation for tropopause- $30 \mathrm{~km}$ is more remakable(45\%) than 13.5$30 \mathrm{~km}$, and that for $20-30 \mathrm{~km}$ almost entirely disappears. As pointed out later, the seasonal variation occurs in the main aerosol layer situated in the altitudes of $16-19 \mathrm{~km}$.

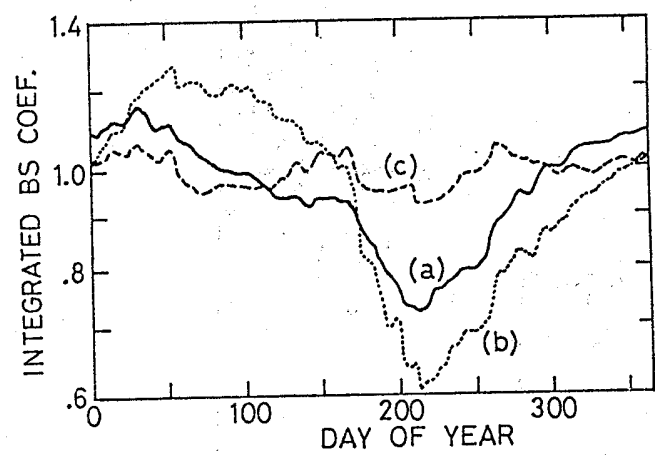

Fig. 3. 90-days running mean annual variation of the ratio to decay curve for the integrated aerosol backscattering coefficient. (a) integration range $13.5-30 \mathrm{~km}$, (b) tropopause-30km, and (c) $20-30 \mathrm{~km}$.

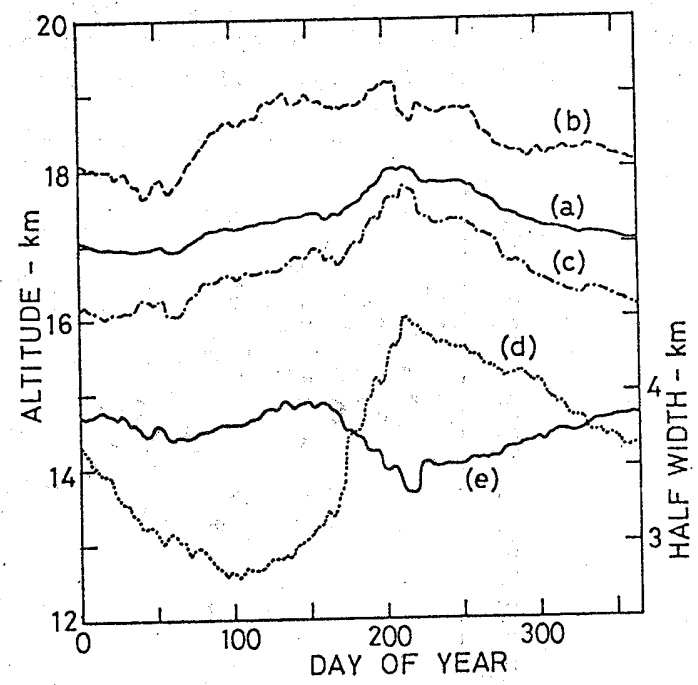

Fig. 4. 90-days running mean annual variation. (a) centroid altitude of columnar content $13.5-30 \mathrm{~km}$, (b) altitude of peak aerosol mixing ratio, (c) altitude of peak aerosol content, (d) tropopause altitude, and (e) altitude width in which half of aerosol content $13.5-30 \mathrm{~km}$ is included. 
Information on the altitudes is also analyzed similarly as above. Figure 4 shows five curves respectively representing 90-days running mean variations in altitude or altitude range. The upper full curve (a) is the centroid of aerosol column content in 13.5-30 km, and the broken (b) and dotted-broken (c) curves are respectively for the peaks of backscattering ratio (mixing ratio) and of backscattering coefficient (content in unit volume). The dotted curve (d), shown as a reference, is the tropopause altitude obtained from the aerological data at Hamamatsu, about $30 \mathrm{~km}$ east of Toyokawa, at 21:00 on the same days as the lidar observations. These altitudes indicate more or less the summer maximum. The main reason of marked annual variation of columnar content above tropopause is the seasonal change of tropopause height. The lower full curve (e) is the altitude width within which half of aerosol content in $13.5-30 \mathrm{~km}$ is included. The width is $3.5-4 \mathrm{~km}$ and indicates little seasonal variation.

4. Correlation among parameters

The correlations among some parameters are analyzed. The parameters and their abbreviations used here are as follows.

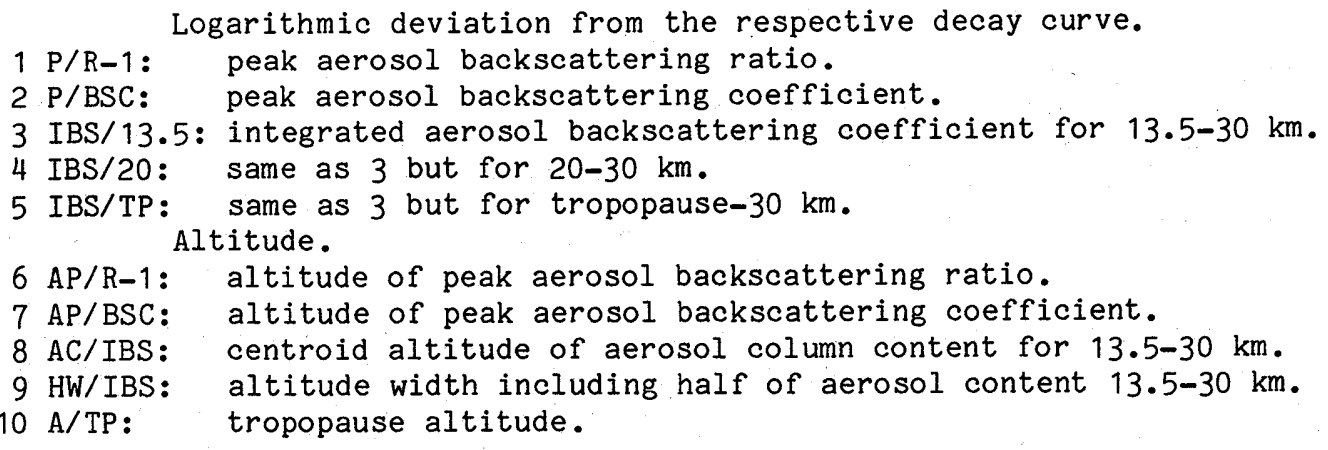

The results of correlation coefficient calculation are given in Table 1 together with the mean and standard deviation of each parameter. The case that the absolute values of coefficient are more than 0.6 is shown in boldfaced figures.

From Table 1 we can see following features.

TABLE 1. Correlation Coefficients among Parameters.

\begin{tabular}{|c|c|c|c|c|c|c|c|c|c|c|}
\hline $\begin{array}{c}\mathrm{Nr} \\
\text { Parameter }\end{array}$ & $\begin{array}{c}1 \\
P / \\
R-1 \\
1.0 \\
\times 1.24\end{array}$ & $\begin{array}{c}2 \\
\text { P/ } \\
\text { BSC } \\
1.0 \\
\times 1.27\end{array}$ & $\begin{array}{c}3 \\
\text { IBS } \\
13.5 \\
1.0 \\
\times 1.26\end{array}$ & $\begin{array}{c}4 \\
\text { IBS } / \\
20 \\
1.0 \\
\times 1.42\end{array}$ & $\begin{array}{c}5 \\
\text { IBS/ } \\
\text { TP } \\
1.0 \\
\times 1.49\end{array}$ & $\begin{array}{r}6 \\
\mathrm{AP} / \\
\mathrm{R}-1 \\
18.3 \\
1.7 \\
\mathrm{~km} \\
\end{array}$ & $\begin{array}{r}7 \\
\text { AP' } \\
\text { BSC } \\
16.5 \\
1.3 \\
\mathrm{~km} \\
\end{array}$ & $\begin{array}{r}8 \\
\text { AC/ } \\
\text { IBS } \\
17.2 \\
0.7 \\
\mathrm{~km} \\
\end{array}$ & $\begin{array}{r}9 \\
\text { HW/ } \\
\text { IBS } \\
3.8 \\
0.6 \\
\mathrm{~km} \\
\end{array}$ & $\begin{array}{r}10 \\
\mathrm{~A} / \\
\mathrm{TP} \\
14.0 \\
2.3 \\
\mathrm{~km}\end{array}$ \\
\hline Parameter & \multicolumn{10}{|c|}{ Correlation Coefficient $\times 100$} \\
\hline 1. $P / R-1$ & & 67 & 62 & 44 & 31 & 7 & 18 & 11 & 8. & -2 \\
\hline 2. $\mathrm{P} / \mathrm{BSC}$ & 67 & & 83 & 16 & 41 & -35 & -45 & -53 & -12 & -3 \\
\hline 3. IBS $/ 13.5$ & 62 & 83 & & 47 & 52 & -13 & -48 & -41 & 17 & -4 \\
\hline 4.IBS $/ 2$ & 44 & 16 & 47 & & 35 & 37 & 11 & 43 & 57 & -6 \\
\hline 5. IBS/TP & 31 & 41 & 52 & 35 & & 1 & -25 & -21 & 23 & -82 \\
\hline 6. $A P / R-1$ & 7 & -35 & -13 & 37 & 1 & & 26 & 55 & 58 & -14 \\
\hline 7. $\mathrm{AP} / \mathrm{BSC}$ & 18 & -45 & -48 & 11 & -25 & 26 & & 77 & -7 & 1 \\
\hline 8. $\mathrm{AC} / \mathrm{IBS}$ & 11 & 53 & -41 & 43 & -21 & 55 & 77 & & 18 & 5 \\
\hline 9. HW/IBS & 8 & -12 & 17 & 57 & 23 & 58 & -7 & 18 & & -29 \\
\hline 10. A/TP & -2 & -3 & -4 & -6 & -82 & -14 & 1 & 5 & -29 & \\
\hline
\end{tabular}




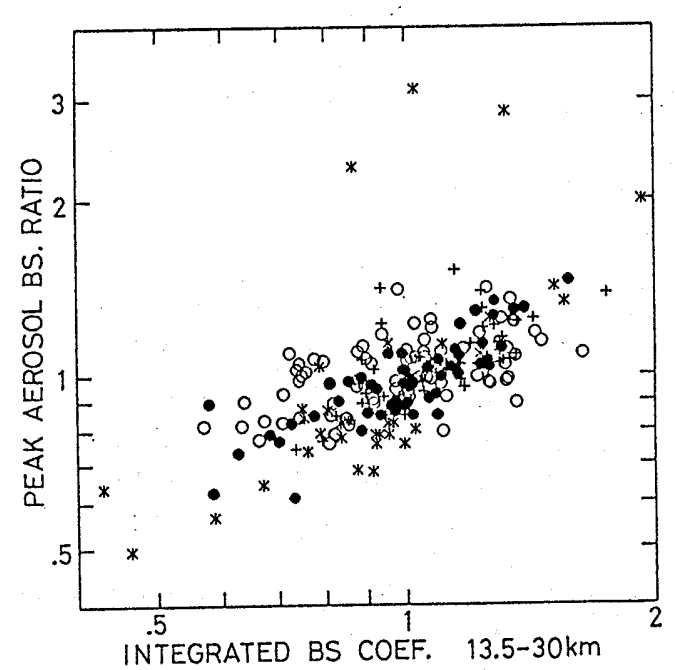

Fig. 5. Correlation between the ratios to the respective decay curves for integrated aerosol backscattering coefficient $13.5-30 \mathrm{~km}$ and for peak value of aerosol backscattering ratio.

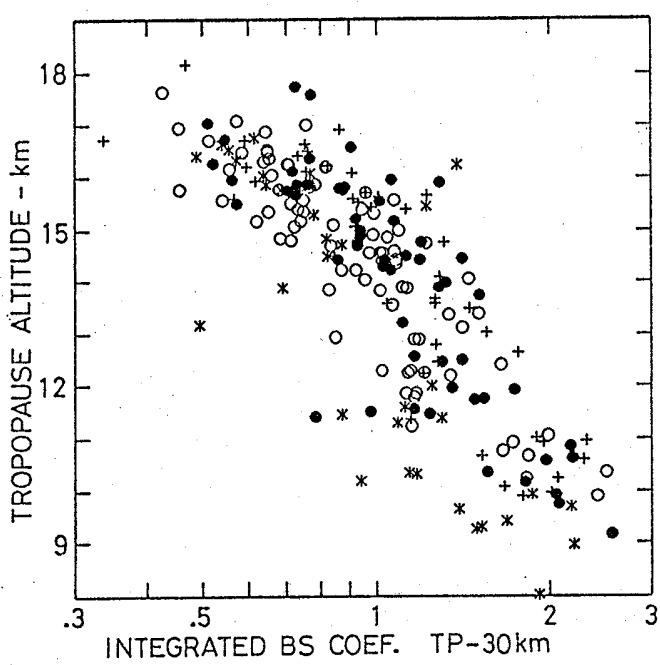

Fig. 6. Correlation between the ratio to decay curve for integrated aerosol backscattering coefficient of tropopause $-30 \mathrm{~km}$ and the tropopause altitude. Different marks correspond to respective years same as in Fig. 2.

Integration range to give the aerosol content most correlative to $\mathrm{P} / \mathrm{R}-1$ or $\mathrm{P} / \mathrm{BSC}$ is $13.5-30 \mathrm{~km}$. Figure 5 shows a very good correlation between the corresponding data of $\mathrm{P} / \mathrm{R}-1$ and IBS/13.5. Exceptional 3 points ( $*$ ) locating up apart from the group are under the influence of Ruiz eruption. On the contrary to this, the content integrated above tropopause (IBS/TP) is neither correlated with $\mathrm{P} / \mathrm{R}-1$ nor $\mathrm{P} / \mathrm{BSC}$. In this sense the representative for stratospheric aerosol content is better to take the integration range above around $13.5 \mathrm{~km}$ rather than above tropopause.

There is a considerable correlation between the altitudes AC/IBS and $\mathrm{AP} / \mathrm{BSC}$ or $\mathrm{AP} / \mathrm{R}-1$. This also assures the pertinence of taking the integration range of $13.5-30 \mathrm{~km}$ to represent the total aerosol content.

There is high negative correlation between IBS/TP and A/TP as shown in Fig. 6. It is a similar result as that reported by Hofmann et al.(1976). This does not always mean in the present case, however, that the tropopause altitude immediately controls the total aerosol content. It is to be noted that the high negative correlation rather comes from the reducing technique in which the higher tropopause results in the shorter integration range. The range adopted for integration just discards the aerosols below tropopause, where aerosols seem to distribute almost independent of day-by-day up and down of tropopause, although it does not deny that the variation of tropopause altitude in longer or seasonal time scale may be the main cause of removing aerosols from the stratosphere.

5. Concluding remarks

It is not always easy to estimate how long the influence of El Chichon eruption had really remained in the stratospheric aerosols, but the steady decay trend after the event had lasted until at least the end of 1985 without any appreciable disturbances which might possibly result from the 
other volcanic activities. The seasonal variation is superposed on the decay trend of stratospheric aerosols. The magnitude of variation is estimated by taking deviation of individual data from a properly assumed decay curve. It clearly shows the winter maximum and summer minimum, which agrees the results on seasonal variations so far reported. It is notable that the amplitude of annual variation (about 25\%) is of almost same order every year notwithstanding very wide change in the absolute aerosol content during 4 years.

Corresponding to the seasonal variation of aerosol content, the centroid altitude for $13.5-30 \mathrm{~km}$ aerosol distribution also varies, on average, from $17 \mathrm{~km}$ in winter to $18 \mathrm{~km}$ in summer. This variation is rather small, and if we assume that the aerosol layer of constant mixing ratio rises and falls within this altitude difference in the course of a year, the amplitude of annual variation of aerosol content is only $9 \%$. For the cause of seasonal variation further studies are required, and the observed and analyzed results are presented here.

Acknowledgements. This work was partly supported by the Grant-in-Aid for Scientific Research from the Ministry of Education, Science and Culture of Japan.

Appendix. Relation between the decay expressions for $\log \{I B S C\}$ and for IBSC

The expression in the paragraph 2 is rewritten as

$$
B=B_{1} B_{0} \exp (-t / T)
$$

where $B=\operatorname{IBSC}(t), B_{1}=\operatorname{IBSC}(t=\infty)$, and $B_{0}=\{\operatorname{IBSC}(t=0)\} /\{\operatorname{IBSC}(t=\infty)\}$. The instantaneous decay constant $\tau$ for $B$ is defined as the time interval in which $B$ reaches the final value $B_{1}$ if the time derivative $d B / d t$ at $t$ is maintained. Then

$$
\tau=T\{1-(1 / F)\} / \log F \text {, where } F=B_{0} \exp (-t / T) \text {. }
$$

If we take $t$ approaching infinity, $\tau$ approaches $T$.

\section{References}

Bigg,E.K., Size distributions of stratospheric aerosols and their variations with altitude and time, J. Atm. Sci., 33, 1080-1086, 1976.

Hofmann,D.J., J.M.Rosen, T.J.Pepin, and R.G.Pinnick, Stratospheric aerosol measurements I: Time variations at northern middle latitudes, J. Atm. Sci., 32, 1446-1456, 1975.

Hofmann,D.J., J.M.Rosen, J.M.Kiernan, and J.Laby, Stratospheric aerosol measurements IV: Global time variations of the aerosol burden and source considerations, J. Atm. Sci., 33, 1782-1788, 1976.

Hofmann,D.J. and J.M.Rosen, on the prolonged lifetime of the El Chichon sulfuric acid aerosol cloud, J. Geophys. Res., 92, 9825-9830,1987.

Iwasaka,Y., Variation of stratospheric aerosol content measured by laser radar, Part I: Seasonal variation of aerosol content and flux of sulfur compounds from troposphere into stratosphere, J. Met. Soc. Jpn., 59, 439-445, 1981. 
Iwata,A., Y.Kondo, and M.Takagi, A laser radar system for the observation of minor atmospheric constituents in the stratosphere, Proc. Res. Inst. Atmos., Nagoya Univ., 30, 25-35, 1983.

I wata,A. and M.Takagi, Lidar observation of decaying El Chichon eruption cloud over Toyokawa, Japan $\left(35^{\circ} \mathrm{N}\right)$, Res. Lett. Atmos. Elect., 4, 11-16, 1984 .

Iwata,A., M.Takagi, Y.Kondo, and Y.Morita, Recent behaviors of stratospheric aerosols as observed by lidar, MAP Symposium IV, Inst. Space Astron. Sci., 107-109, 1986.

Reiter,R., H.Jager, W.Carnuth, and W.Funk, The stratospheric aerosol layer observed by lidar since october 1976. A contribution to the problem of hemispheric climate, Arch. Met. Geoph. Biokl., B27, 121-149, 1979.

(Received October 18, 1988;

revised December 3, 1988;

accepted December 7,1988 ) 